\title{
LA CONTRAUTOPÍA PORNOGRÁFICA EN LA MISTERIOSA DESAPARICIÓN DE LA MARQUESITA DE LORIA
}

\author{
MARÍA LUISA MARTÍNEZ M. \\ Universidad de Concepción, Chile \\ marmartinez@udec.cl
}

\section{RESUMEN}

La misteriosa desaparición de la marquesita de Loria (1980) se presenta como relato excitante que deviene novela fantástica a partir de la postergación de lo erótico y se resuelve como una contrautopía pornográfica.

Palabras clave: José Donoso, narrativa chilena, utopía, heterotopía.

\section{ABSTRACT}

The mysterious disappearance of the marquesita of Loria (1980) is presented as an exciting tale that becomes a fantasy novel when the erotic is postponed and is resolved as a pornographic counter-utopia.

Keywords: José Donoso, chilean narrative, utopia, heterotopia.

El deseo, el juego erótico y la pasión sexual son algunos de los elementos presentes en La misteriosa desaparición de la marquesita de Loria, novela de José Donoso ${ }^{1}$ publicada en 1980. La presencia de tales ingredientes ha hecho que una parte de la crítica vea en ella un texto erótico que continúa con la exposición de una simbología propia de la escritura donosiana y que consiste en la irrupción de los perros (dobles de los protagonistas) como fuerza esencial que trasciende lo sexual y que, finalmente, actúan como mediadores entre Eros y Tanatos. Otras perspectivas críticas han comprendido este elemento erótico como telón de fondo para una narración que se resuelve como novela de denuncia social y como texto que nos conduce desde un género paraliterario, el erótico, hasta otro literario por excelencia, el fantástico. Estos elementos se conjugan, sin duda, en La misteriosa desaparición de la marquesita de Loria y resaltan la ambigüedad de la novela.

El texto se abre con la presentación de Blanca Arias, hija de un diplomático hispanoamericano, «de aquellos que tras una gestión tan breve como vacía en Madrid no dejaban otro rastro de su paso por la Villa y Corte que una bonita hija casada con un título» $(1997, \text { p. 11) })^{2}$ y su encumbramiento social, tras el matrimonio con Paquito Loria y la prematura muerte de este último, como la joven marquesita viuda de Loria. La narración sigue luego el aprendizaje del placer de Blanca Arias, búsqueda insatisfecha hasta ese momento debido a la impotencia de Paquito, y la determinación de la protagonista para que «desde su espléndida viudez, protegida por las rejas de las ventanas de su palacete, oteara el horizonte con el fin de elegir acertadamente aquello que más placer podía procurarle» (p.
María Luisa Martínez M.

Doctora en Literatura Latinoamericana por la Universidad de Concepción, Chile. Sus líneas de investigación prioritarias abordan el estudio de las relaciones entre literatura y utopía, así como literatura e imaginación pornográfica. $\mathrm{Su}$ tesis doctoral, que fue destacada por la Red Universitaria Cruz del Sur y obtuvo el primer lugar en el concurso Tesis Doctorales (Universidad de Concepción, 2010) examina dichas relaciones en el marco de la escritura narrativa de Mario Vargas Llosa. Ha publicado artículos en revistas especializadas y próximamente aparecerá su libro titulado La trampa de los sueños. La narrativa de Mario Vargas Llo$s a$. Es profesora del Departamento de Español de la Universidad de Concepción.

1

José Donoso (1924-1996), destacado escritor y periodista chileno, es uno de los miembros más importantes de la generación del '50 y una de las principales figuras del boom latinoamericano. Se radicó en España entre los años 1967 y 1981, país en el que se autoexilió en rechazo al Gobierno Militar de Augusto Pinochet. Su obra se caracteriza por mostrar la decadencia de la clase alta chilena, a la que pertenecía, y por un magistral desarrollo de las técnicas narrativas. Entre sus novelas principales se encuentran Coronación (1957) El lugar sin límites (1965), El obsceno pájaro de la noche (1970), Casa de campo (1978) y El jardín de al lado (1981). Fue distinguido con el Premio Municipal de Santiago (1965) y con el Premio Nacional de Literatura (1990), entre otros.

2

Las citas de La misteriosa desaparición de la marquesita de Loria van acompañadas sólo del número de página (ver referencias bibliográficas).
La contrautopía pornográfica en misteriosa desaparición de la Marquesita de Loria

MARÍA LUISA MARTÍNEZ M. 


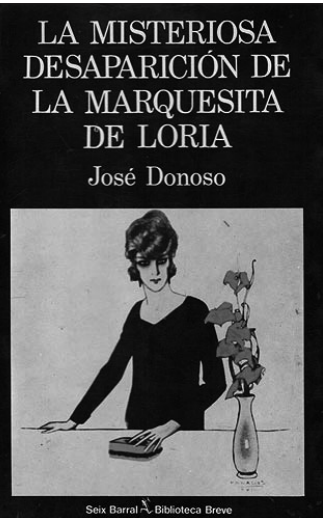

Cubierta La misteriosa desapari ción de la Marquesita de Loria.

3

El lector implícito es, en términos de Iser, «el esbozo del rol del lector en el texto" (1987, p. 69). Éste determina la recepción que el lector real hace del relato. Si el lector implícito y el lector rea coinciden en los sentidos sugeridos por el texto, las expectativas de este último se satisfacen y se acepta la visión de mundo planteada en la novela.

La contrautopía pornográfica en La misteriosa desaparición de la Marquesita de Loria

MARÍA LUISA MARTÍNEZ M.
12). La marquesita, cansada de prolegómenos masturbatorios e inconducentes, resuelve su vida, de ahí en adelante, como experimentación y aprendizaje sexual:

Las escenas que estructuran el libro presentan in crescendo prácticas sexuales de todo tipo, que van desde los tocamientos de la infancia, la masturbación propia y recíproca, el voyeurismo y la gerontofilia, a la coprolalia, el sexo oral y anal, la violación, el fetichismo, el travestismo, la zoofilia, el troilismo y el amor homosexual en su vertiente lésbica (Noguerol, 1997, p. 232).

Hasta ese momento, la novela se nos ofrece como relato excitante, pero ninguno de los amantes de Blanca - ni Paquito, ni Mamerto Sosa, ni Almanza, ni Archibaldo Arenas, ni Tere Castillo, ni Casilda o Mario - logra satisfacer las expectativas de la protagonista. La marquesita descubre efectivamente el placer, pero éste es sólo un espejismo de plenitud. Los relatos excitantes se constituyen en gran medida a partir de la recepción del texto, determinándose en función del comportamiento del lector. La misteriosa desaparición de la marquesita de Loria debe considerarse, en ese sentido, a partir de la intención narrativa que determina al lector implícito ${ }^{3}$. El lector de la novela de Donoso será un lector de literatura excitante desde el momento en que acepta las primeras páginas del texto e incluso su título, ya que la palabra marquesita posee reminiscencias perversas que remiten a clichés de la literatura excitante y que preorientan la lectura: «La protagonista es una transfiguración de las aristócratas modernistas» (Noguerol, 1997, p. 234). Rita Gnutzmann señala respecto del carácter apelativo de los textos que "para ser capaz de encontrar al "lector implícito" tenemos que fijarnos en el narrador [ya que es él quien ordena el texto o, en términos de Iser, ofrece la "preorientación" textual]" (1991, p. 9) y, en ese sentido, La misteriosa desaparición de la marquesita de Loria se organiza, en un principio, como relato excitante dirigido a lectores de ese género. Sin embargo, la búsqueda de satisfacción sexual de la protagonista es reemplazada por una intención mucho más profunda, de orden existencial, que altera el horizonte de expectativas de la lectura. Blanca, hastiada de su vida protegida y previsible, incluso en sus excesos y transgresiones, sucumbe finalmente a la fascinación que ejerce sobre ella la llegada de
Luna, el perro de ojos gris-limón que eclipsa sus deseos anteriores, desmantela su vida y otorga una nueva dirección al relato. El erotismo predominante en la primera parte de la narración va cediendo paso, paulatinamente, a elementos que desvirtúan la lectura inicial del texto y lo hacen ingresar definitivamente en el género fantástico. Lo excitante y lo fantástico se conjugan en un relato dominado por la indeterminación, pero capaz de normalizar a partir de ciertos indicios. La novela termina con el paseo de Blanca y Luna por el Retiro en una noche lluviosa; Mario, el chofer, intenta impedir que la marquesita se baje del auto, apelando a la lluvia y al peligro que suponen figuras de gitanos que él ha visto agazapadas detrás de los árboles. El forcejeo entre ambos culmina con la violación consentida en el asiento trasero del Isotta Fraschini y con la posterior resolución de Blanca de «seguir al perro que parecía ofrecerle algo más» (p. 160) en la espesura de la noche, en la que es devorada por una figura monstruosa que surge de las sombras. La marquesita desaparece sin dejar rastros, a excepción de unos pocos objetos personales: la Baby Browning con empuñadura de nácar, la hebilla de plata de su cloche negra, un zapato francés y el Patek Philippe. Mario, el chofer de la marquesita, da esta versión a la policía, quien lo condena por un supuesto crimen pasional y la novela se cierra en el aparente misterio.

Iser plantea que el texto literario toma elementos del mundo vital y los hace participar de una ficción: «Las situaciones del mundo vital son siempre reales y los textos literarios son, por el contrario, fictivos; por ello, sólo se pueden cimentar en el proceso de la lectura, pero no en el mundo» (1993, p. 103). El lector, siguiendo a Iser, actualiza el texto y, para referirse a lo que éste transmite, proyecta el mundo narrado a su propia experiencia. De esta tensión entre la experiencia propia con la experiencia potencial que el texto sugiere surgen dos reacciones extremas: una en la que el relato se presenta como trivial, porque ambas experiencias coinciden, y otra en la que éste se nos ofrece como fantástico, porque la experiencia potencial contradice nuestro mundo. Sin embargo, la indeterminación del texto es posible normalizarla respondiendo a su carácter apelativo y llenando sus espacios vacíos. De esta manera, dado que los hechos narrados en La misteriosa desaparición de la marquesita de Loria no son reductibles a 
objetos reales y concretos, el lector debe ubicarlos dentro del género fantástico ${ }^{4}$, valerse de los indicios excitantes que la novela ofrece y relacionar éstos con los componentes utópicos del texto. Carolin Fischer señala que la protagonista de un relato excitante se libera de las convenciones sociales y, cuando eso sucede, no persigue un propósito procreador como sería de esperar: "An diesem Punkt werden zwei Orientierungen der erregenden Literatur deutlich: Provokation und Utopie» (1997, p. 18). La liberación de Blanca Arias corresponde a este segundo tipo de orientación, la utópica, que culmina en un proceso de disolución del yo, el que se efectúa a través de su desaparición simbólica.

Los textos de imaginación pornográfica, siguiendo la terminología de Susan Sontag, se rigen por una obsesión sexual que adquiere proporciones utópicas o, más precisamente, la imaginación pornográfica se origina a partir de un supuesto utópico, un volcamiento exclusivo en el placer, en el vaciamiento individual a partir de la experiencia erótica y en una búsqueda exclusiva del goce sexual. La fantasía pornográfica se libera de limitaciones físicas, religiosas o morales que puedan perturbar esa búsqueda y los excesos narrados se despliegan en un lugar utópico y atemporal, que es el ambiente de novelas de imaginación pornográfica como Historia de $O$ de Pauline Réage, Historia del ojo de Bataille, o los textos del marqués de Sade, «el paisaje onírico y ahistórico donde se sitúa la acción, el tiempo congelado de manera peculiar donde se ejecutan los actos» (Sontag, 1997, p. 72). Es ahí donde los personajes, liberados de las ataduras de las convenciones sociales, se rebelan contra toda normativa que intente aprisionarlos y se entregan con agitación frenética al horror. El clima emocional que acompaña a esta liberación neutraliza los afectos y emociones y enfrenta a los personajes a la nada, que es una anticipación sensual de la muerte. Ese estado de agonía es equivalente a un proceso de vaciamiento personal, como señala Sontag: «En la medida en que un fuerte sentimiento sexual implica un grado obsesivo de atención, también abarca experiencias en las cuales el individuo puede

4

Todorov plantea que el problema medular de lo fantástico, género que oscila entre lo

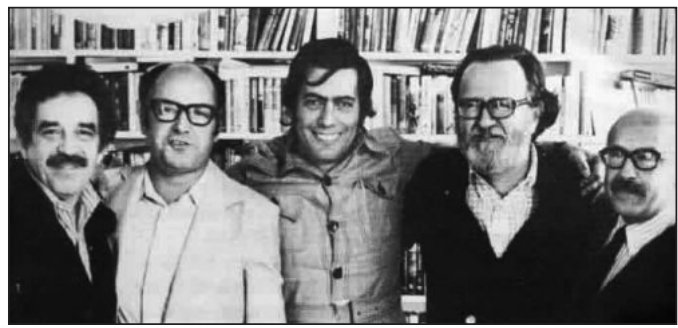

Donoso con García Márquez y Vargas Llosa.

sentir que está perdiendo su yo» $(1997$, p. 90). Esa angustia existencial se experimenta como disolución, aspecto claramente identificable en la novela de Donoso.

La misteriosa desaparición de la marquesita de Loria es un texto autorreferencial, en el que el efecto excitante del relato es tematizado en el interior de la novela. Blanca Arias, la protagonista femenina ${ }^{5}$, se inicia en un gradual conocimiento del deseo, primero a través de la observación, y luego a través de la acción. La actitud voyeurista al inicio de su recorrido sensual es una invitación al lector para que participe de la solución propuesta frente al deseo. Los personajes, al inicio de la novela, acuden a la ópera y presentan una sucesión de actitudes voyeuristas y masturbatorias que incitan al lector a imitar el modelo sugerido. Blanca observa a Elsa y Lohengrin a orillas del lago y, provocada tanto por la pasión de la escena representada como por los roces de Paquito, simula una masturbación a su amante haciendo un tubo con el programa. Paquito, a su vez, observa este simulacro y se ve impelido a imitar este acto masturbatorio en sí mismo:

Comprendiendo la sugerencia del programa enhiesto, con la mano libre se buscó a sí mismo, soñando que la caricia que Blanca le prodigaba al programa se la estaba prodigando a él, para así alcanzar un éxtasis de amor paralelo al de Elsa y Lohengrin a orillas del río Brabante (p. 23).

Luego Almanza, otro voyeur, «un claro ejemplo de la función que cumple el mirón en el texto erótico, verdadero catalizador del deseo del lector, al que proporciona una satisfacción adicional» (Noguerol, 1997, p. 238), illusion of the senses, a product of the imagination -and laws of the world then remain what they are; or else the event has indeed taken place, it is an integral part of reality- but then this reality is controlled by laws unknown to us. Either the devil is an illusion, an imaginary being; or else he really exists, precisely like other living beings - with this reservation, that we encounter him infrequently» (1975, p. 25). Al final de un texto, el lector debe optar por una solución que permita explicar los fenómenos descritos. Se entra en el terreno de lo extraño si las leyes de la realidad permanecen inmutables; se entra en el terreno de lo maravilloso si, por el contrario, las leyes de esta realidad deben ser consideradas para explicar estos fenómenos. De esta manera, el género fantástico está en la frontera entre ambos géneros. La misteriosa desaparición de la marquesita de Loria transita estos mundos, especialmente el mundo de lo desconocido, porque los hechos narrados son inquietantes, perturbadores $y$ extraordinarios $y$ despiertan en el lector, por momentos, una reacción cercana al miedo.

5

Carolin Fischer señala en su texto Gärten der Lust que una mujer es protagonista en un relato excitante, porque la fantasía de un hombre heterosexual siente mayor interés en una mujer que lo libere del rol tradicional de seductor para convertirlo en objeto de su deseo, mientras que las lectoras pueden sentirse identificadas con la protagonista. La novela de Donoso posee un narrador heterodiegético, omnisciente, que alcanza incluso a los monólogos interiores de la protagonista. Hay inclusión de pasajes en estilo indirecto libre, por ejemplo cuando Almanza insulta a Blanca y sus palabras cumplen la función de ser un ingrediente de violencia que actúa como acicate sexual: "puta, cursi, entrometida, creía que él no se daba cuenta, basta ya de pretensiones, si las ganas se le notaban en el olor que se sentía desde lejos» (p. 76). También hay uso del diálogo en momentos de pasión como una forma de apelación directa a los destinatarios para, así, invalidar sus objeciones. devils, sylphides or vampires, there occurs an event which cannot be explained by the laws of this same familiar world. The person who experiences the event must opt for one of two possible solutions: either he is the victim of an

\footnotetext{
La contrautopía pornográfica en La misteriosa desaparición de la Marquesita de Loria

MARÍA LUISA MARTÍNEZ M.
} 
Solotorevsky señala las connotaciones etimológicas del nombre del notario: "el contraste entre la edad avanzada del personaje y su eficacia sexual, provoca un efecto humorístico, el cual resulta acrecentado por cuanto en el nivel fónico dicho antropónimo evocaría la imagen del niño [mam=mamar] y del muerto [erto]» $(1997$, p. 86).
La contrautopía pornográfica en a misteriosa desaparición de la Marquesita de Loria

MARÍA LUISA MARTÍNEZ M. imita a Blanca y Paquito, y se masturba recordando el pasado, cuando él protagonizó una situación análoga con Casilda en el mismo palco:

No había perdido ni un gesto, ni un movimiento, ni un segundo del tierno devaneo de esos dos palomos... embelesado, rejuvenecido por el ritmo sutil, pero enloquecedor de los jóvenes, que se iba haciendo más y más frenético a medida que las sudorosas exigencias de amor crecían en escena, el conde se unió a la exquisita Blanca, a Paquito, a la música que los transportaba en su sensualidad declamatoria, que él iba siguiendo y compartiendo (p. 23).

Finalmente, el lector es invitado a formar parte en esta cadena de autosatisfacción a partir de la presentación de un deseo que busca excitar.

La marquesita de Loria tropieza en su búsqueda sexual con Archibaldo Arenas, «pésimo pintor; se ha hecho su fama pintando a las señoras ricachonas más flacas de lo que son y sus perlas más gordas» (p. 132), quien, sin embargo, seduce a la marquesita con sus ojos enigmáticos que cambian significativamente de color en diferentes momentos de la narración. En el primer encuentro por el Retiro, el pintor tiene los ojos negros, pero la segunda vez son de color gris, igual que Luna, el perro que fascina a Blanca. Pearson señala que «los ojos de los personajes y del perro indican, en cierto modo, el desdoblamiento que ocurre en la novela» (1982, p. 13). La identificación entre Archibaldo Arenas y Luna es notoria: «Este personaje es identificado desde el primer momento con la animalidad de su perro Luna, figura que a partir de ahora cobra un progresivo protagonismo en la novela» (Noguerol, 1997, p. 237). El encuentro con el pintor y su perro excitan tanto a Blanca, que debe escapar de ellos; la huida, sin embargo, es infructuosa, porque Archibaldo Arenas le envía el perro a la marquesita -o eso cree ellacomo emisario de un mensaje misterioso que preanuncia el encuentro sexual entre ambos. La búsqueda del goce sexual de Blanca con diferentes amantes, primero Paquito, después Mamerto Sosa, luego Almanza y posteriormente Archibaldo Arenas es satisfactoria, pero sólo en apariencia. La convención del matrimonio con Paquito había matado la espontaneidad sexual, probable causa de su impotencia; aún así, la marquesita logra sacar el mayor provecho posible a sus simulaciones del acto sexual. La relación con el notario también resulta placentera, a pesar de su edad y la pequeñez de sus atributos: "Apareció diminuto aunque, era evidente, asombrosamente eficaz para su edad, el pequeño pero agresivo cuerno indomable, justa la medida, ni más ni menos, de lo que ella en ese momento necesitaba ${ }^{6} »$ (p. 53). Blanca adquiere experiencia y recibe placer de Almanza:

Él, entonces, esta vez, la fue penetrando suavemente, como tan bien sabía -incluso pareciendo no tener intenciones de hacerlo- hasta una profundidad de su persona que la marquesita viuda de Loria ni siquiera sospechaba poseer, durante un tiempo que se prolongó anochecido, caliente y húmedo, hasta lo que a ambos les pareció una versión perfectamente satisfactoria del infinito (p. 77).

Tanto el notario como el conde son sustitutos del deseo que Blanca anticipa de su encuentro con Archibaldo Arenas, quien parece representar la respuesta total a los deseos de la marquesita. Mamerto Sosa y Almanza son sustitutos del pintor, la necesaria iniciación antes de «ese largo placer que jamás se volvería a repetir igual» (p. 108), pero finalmente todos los amantes de Blanca son insatisfactorios. Todo ha sido un engaño, a pesar de la satisfacción obtenida. La performance sexual de Almanza es sólo una representación del placer, un espejismo de infinito, pero al menos está dedicada exclusivamente a ella y a la satisfacción de sus sentidos, generosidad de la que Archibaldo carece y esta razón justifica la sustitución de unos por otros: «La imaginación pornográfica tiende a convertir a una persona en intercambiable con otra y a todas las personas intercambiables con objetos» (Sontag, 1997, p. 82). Luna suplanta a todos los amantes previos y posteriores a su llegada; así, Tere Castillo, Casilda y Mario tampoco lograrán retener a Blanca. El perro se presenta como la verdadera liberación de las ataduras que pudieran ligar todavía a la marquesita a un mundo de significaciones dominantes: «Pero el objeto del deseo en verdad no será el hombre, sino el can. O será el can -con sus ojos gris-limón como el agua del estanque al atardecer, como la luna- la simbolización o el agente del deseo desenfrenado» (Valenzuela, 1997, p. 1006). El objeto del deseo de Blanca se desplaza por un camino sin retorno desde el amante de turno, finalmente circunstancial y fugaz, hacia la obsesión permanente por el perro y el lector espera la concretización de la 
unión zoofílica que cumpliría sus expectativas de lectura. Sin embargo, nunca se produce la esperada unión sexual entre Blanca y Luna, y la novela se desvía de la orientación textual excitante para ingresar definitivamente en el terreno de lo fantástico, como señala Solotorevsky al referirse a la frustración de lo erótico dentro de la novela: «Como posible culminación del erotismo, la llegada del perro -Luna- haría esperar la unión sexual entre él y Blanca, pero, precisamente entonces, el texto burlará las expectativas del lector, desviándose diegética y genéricamente» (1997, p. 87).

Luna no es propiamente un doble de los protagonistas, más bien es uno de sus rostros, vacío e inhumano. Blanca cree al principio que los ojos del perro, dos lunas gemelas, son las dos lunas de su infancia y, al mismo tiempo, anticipan su unión con el pintor, quien ha enviado a Luna como su emisario. Cuando ve por tercera vez a Archibaldo, éste ha recuperado el color negro de sus ojos de la primera vez, porque mandó el color gris-limón del segundo encuentro con el perro. La unión sexual con Archibaldo desconcierta a la marquesita, quien espera ser asaltada por el pintor y que éste «se echara de inmediato sobre ella para devorarla como un lobo» (p. 104), pero no sucede así. La protagonista busca en Archibaldo un cierto hálito siniestro y nocturno, que asocia con la luna de su infancia, presencia fundamental en los pasajes eróticos y fantásticos de la novela. Los retozos masturbatorios de Blanca evocan su niñez, regida por la presencia del astro:

El juego en la oscuridad de una niñez tropical recobrada frente a esas dos lunas, castas y gemelas que la observaban -una luna muy baja, allá en el cielo junto al horizonte; otra luna reflejada en el caluroso mar del nocturno caribeño, dos lunas que eran una sola (p. 90).

La luna ejerce una fuerza sexual que se conjuga con un misterioso efecto sedante: «Las mestizas de su niñez, en las noches de miedo, le señalaban las dos lunas idénticas en el horizonte para calmarla» (p. 117). La atracción por la luna explica en parte la atracción ejercida por el misterio de los ojos del pintor, pero cuando Blanca lo despoja de ese aura y comprende que él es alguien común $\mathrm{y}$ corriente, un hombre que quiere casarse y tener hijos, un pintor mediocre que imita a Anglada Camarasa, pierde irreversiblemente el interés sexual y espiritual en él, y se centra obsesivamente en el perro, quien sí confirma sus expectativas y búsqueda existencial:

Allí estaban esos ojos límpidos como dos continentes en blanco, como páginas sin escribir, como senderos jamás transitados, dos honduras gris-oro que no expresaban nada porque sólo eran, en las que la mente de Blanca podía hundirse y disolverse, o encontrar algo que desde este lado de las lunas gemelas ella no alcanzaba a ver (p. 136).

Lo notable radica en que la disolución de Blanca no tiene su origen en un elemento sexual, sino que nace del horror de los ojos de Luna y su promesa implícita.

El cuerpo, según Foucault, es el lugar de todas las utopías y a partir de él se generan todas las fugas. Tres elementos, sin embargo, recuerdan nuestra realidad concreta y acallan esas utopías que el cuerpo proyecta: el cadáver, los espejos y el amor. Este último actúa como vértice que conecta la tríada, porque encierra la ilusión y la promesa de especularidad a través de una exigencia de muerte para salvarnos de nuestra discontinuidad y continuarnos en otro. La misteriosa desaparición de la marquesita de Loria comprende esa visión foucaultiana del cuerpo, pero amplificada por el exceso en el que un amor torcido desplaza las convenciones amorosas:

Hacer el amor es sentir su cuerpo que se cierra sobre sí, es finalmente existir fuera de toda utopía, con toda su densidad, entre las manos del otro. Bajo los dedos del otro que te recorren, todas las partes invisibles de tu cuerpo se ponen a existir, contra los labios del otro los tuyos se vuelven sensibles, delante de sus ojos semicerrados tu cara adquiere una certidumbre, hay una mirada finalmente para ver tus párpados cerrados (Foucault, 2010, p. 18).

El concepto amoroso es quebrantado en la novela de Donoso por la exclusión de la unión sexual entre Blanca y Luna. El perro desecha violar a Blanca, lo que en última instancia sería un elemento convencional en textos de carácter pornográfico. La postergación y anulación de esta unión cifra la contrautopía donosiana:

Durante un segundo creyó -no temió, porque veía esas dos gotas de luna transparente mirándola- que el perro iba a violarla: hubiera sido por lo menos una forma de tranquilidad, comprender un motivo, tener

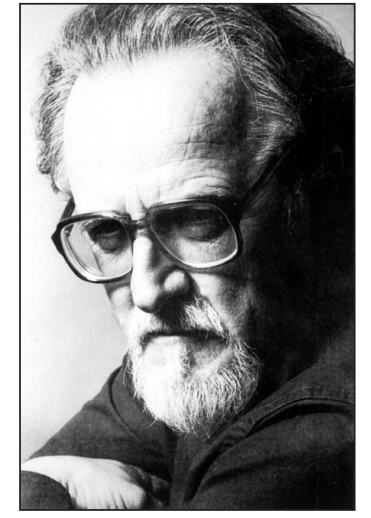

José Donoso. La contrautopía pornográfica en
La misteriosa desaparición de la
Marquesita de Loria

MARÍA LUISA MARTÍNEZ M. 
7

Las utopías se despliegan en un tiempo ucrónico, un tiempo que resiste y se rebela contra las convenciones temporales. El carácter marginal de estos contraespacios expresa una propiedad disolvente. Estas utopías localizadas rondan la muerte en los textos de imaginación pornográfica $y$, en ellos, la degradación adquiere otro matiz.

La contrautopía pornográfica en L misteriosa desaparición de Marquesita de Loria

MARÍA LUISA MARTÍNEZ M. acceso a una explicación, compartir un instinto..., pero no era eso. ¿Qué era...? Y al darse cuenta de que jamás lo sabría, como quien se asoma a un precipicio que no tiene fondo, sintió que la sacudía un feroz escalofrío que culminó en un orgasmo de pavor bajo ese cuerpo al que no podía satisfacer con su sexo capaz de saciar, hasta de matar, a cualquiera (p. 118).

El gran espejo ubicado en la pared frente a la cama para que fuera testigo de los fracasos eróticos de Paquito es reflejo de los convencionalismos que la marquesita rehúye, porque la verdadera transgresión escapa a la búsqueda de la continuidad tradicional. $\mathrm{El}$ amor en los relatos excitantes no busca el reflejo en el otro, sino que intenta capturar una pareja utópica y subversiva, que escape de los formalismos y se proyecte en un trazo que los aleje de la imagen reconocible y atroz que otorgan los espejos. Blanca busca su propia satisfacción y Luna se ajusta a ese propósito, "porque ambos eran como la reflexión de la luz reflejada en el otro» (p. 140), y la especularidad se presenta sólo para intensificar o contribuir a la experiencia individual. La fuga de la marquesita es demónica y solitaria y, en última instancia, busca alejarse del propio rostro, no capturar la imagen que se desprende de él, como se percibe en la irreconocible imagen que proyecta en los espejos: "Vio su cuerpo albo manchado de magulladuras y cardenales, estriado de rasguños, los colmillos de la bestia claramente marcados, una especie de santa trágica, tremendista, tenebrista, una mártir horrorosa y sangrienta» (p. 137).

El orgasmo de pavor de Blanca sintetiza la conjunción entre miedo y placer, dolor y pasión, horror y belleza propios de la literatura pornográfica. La marquesita es presa de una búsqueda existencial a través de los sentidos, que excede la búsqueda burguesa de la felicidad y que se orienta hacia una búsqueda ontológica y utópica que se expresa en la atemporalidad del caos en que Luna deja convertida la habitación de Blanca, una utopía situada o heterotopía, en términos de Foucault, quien aclara que las utopías ${ }^{7}$ se caracterizan por situarse en un no-lugar. Las heterotopías, en cambio, son contraespacios situados, lugares utópicos claramente definidos, zonas de aislamiento que, entre sus características, poseen la propiedad de estar ligadas a un sistema de apertura y cierre que regula la entrada a ellas. La habitación de Blanca es una heterotopía y la anacronía en que la protagonista comienza a desenvolverse, con el elegante reloj destrozado por el perro, otorga al espacio degradado un carácter insular que se potencia con la fortuna arrebatada, el cuerpo golpeado y las bases de su vida desintegradas. La marquesita es el único personaje que tiene acceso a su habitación desde la llegada de Luna; Blanca, al principio, cuando todavía siente su posición en la vida y su casa como ajenas, teme que alguien censure el caos desplegado por la presencia del perro. Luego, a partir del secreto de Luna y del poder que éste le confiere sobre su vida y sus actos, despliega su dominio en actos aparentemente menores, pero que constituyen su nueva fuerza:

Cuando Blanca cerró la puerta de su dormitorio con llave, mandó a Hortensia que no intentara entrar en él hasta su regreso. Todo esto sin darle ninguna explicación. Reflexionó sobre las ventajas que tiene el poder: las acciones de los poderosos, se dijo, no son más que acciones puras -no es necesario justificarlas, simplemente son lo que son (p. 92).

Para Bataille, la base de la vida es la continuidad, la unión de dos seres discontinuos que anhelan la continuidad y que portan en sí mismos la nostalgia de una antigua continuidad, fundamento mismo del erotismo. Esta unión incluye, en su complejidad, un elemento de desorden, un elemento violento, algo pesado y siniestro, el deseo de la muerte propia o del otro: «La pasión nos adentra así en el sufrimiento, puesto que es, en el fondo, la búsqueda de un imposible; y es también, superficialmente, siempre la búsqueda de un acuerdo que depende de condiciones aleatorias» (1997, p. 25). La pasión por Luna explica la liberación de Blanca, construida sobre una utopía de los sentidos en un caos donde ambos son soberanos. Blanca se siente atraída por el poder devastador del perro, que nadie más parece advertir, como si sólo existiera dentro de sí misma y no para el mundo exterior, o como si ella fuera sólo el epíteto de Luna: «Así, Blanca sería un mero pero necesario adjetivo para Luna, la fuerza que la impulsa hacia el agujero negro de su autorrepresentación» (Borinsky, 1997, p. 998). El perro será la verdadera pareja de la marquesita, aquélla por quien se dejará arrastrar en una utopía sensual de la disolución cifrada en una satisfacción sexual siempre frustrada, en una postergación de la muerte: «Cuando el perro 
se dio cuenta de que Blanca se disolvía en el primer espasmo de la noche, la soltó» (p. 136).

La novela narra en el capítulo final la leyenda que todavía corre por Madrid de que las parejas que acuden de noche al Retiro son sorprendidas en el momento del amor por un gran perro gris, de ojos gris-limón, que se aparece como una visión del espanto y los obliga a huir. Los indicios de que se trata de Luna están dados no sólo a través de las características físicas que éste comparte con la imagen espectral y legendaria, sino que, además, a través de la intención del perro de frustrar la culminación sexual de los personajes (la primera aparición de Luna en la mansión de Blanca sorprende a la marquesita mientras se masturba y los ladridos impiden que ella alcance el orgasmo). La repetición de la irrealizada violación a manos del perro es la anticipación sensual de la continuidad que ambos alcanzan sólo al final del relato, cuando Mario ve la figura de la protagonista devorada por una bestia feroz. De esta manera, La misteriosa desaparición de la marquesita de Loria es crónica de una muerte anunciada y esperada, pero que se resuelve como desaparición. El final de de la novela conjuga los elementos eróticos y fantásticos en la violenta unión entre Blanca y Mario. El texto parece sugerir que Luna hace una concesión al permitir la realización sexual de los amantes antes de hacer ingresar a la marquesita en el dominio de lo desconocido. Es interesante observar que Mario, sugerentemente, se abalanza sobre Blanca «acezante como un animal» (p. 159) y la lleva a experimentar un placer violento que «sólo podía permitir que los pálidos ojos de Luna vieran que sentía» (p. 160). Jürgensen señala que, en la literatura pornográfica, la sexualidad es representación de una muerte experimentable y, en ese sentido, sólo la continuidad de Blanca en Luna hará posible su disolución: «Alle Pornografie hat, direkt oder indirekt, mit Auflösung, Hingabe und Tod zu tun. Sie hat die Passion der menschlichen Sterblichkeit zum Inhalt» (1985, p. 13). Luna arrastra a Blanca hacia la muerte, propiedad otorgada por la simbología a los perros: «la primera función mística del perro, universalmente aceptada, es la de psicopompo, guía del hombre en la noche de la muerte, tras haber sido su compañero en el día de la vida» (Chavalier y Cheerbrant, 1995, p. 816). Esta muerte puede ser física, pero fundamentalmente es de su yo. Pérez Blanco señala que la novela de Donoso comparte las constantes propias de los escritores hispanoamericanos, entre ellas la aniquilación simbólica de un grupo, la denuncia de la sociedad chilena frente a su propia identidad y la destrucción de sí misma frente a la llamada del propio ser. Esta lectura da una salida para el misterioso final de la novela: «Si Blanca, símbolo de Hispanoamérica, desaparece y no se encuentra rastro alguno suyo, es porque la descomposición no deja rastro del propio ser» (Pérez Blanco, 1997, p. 400). Atendiendo nuevamente a la simbología y a la onomástica, la luna «simboliza dependencia y el principio femenino (salvo excepciones), así como la periodicidad y la renovación. En este doble aspecto es símbolo de transformación y crecimiento" (Chavalier y Cheerbrant, 1995, p. 658). El verdadero aprendizaje de Blanca no es sexual, sino metafísico, como confirma el final fantástico de la novela. La forma de normalizar el misterio se da a través de la relación de los indicios que el texto ofrece: «La indeterminación, inherente en mayor o menor medida al texto, se manifiesta en las llamadas lagunas (Leerstellen, pasajes vacíos), que incitan al lector a rellenarlas, determinando así de una forma o de otra el sentido de la obra» (Rico, 1983, p. 21). La novela de Donoso se cierra en el misterio no sólo por la desaparición de la marquesita, sino que porque Archibaldo Arenas, bajo una fachada de convencionalismo, casado con Charo, hermana de Blanca, y con muchos niños a su alrededor, está acompañado de Luna, «su gran y fiel perro gris» (p. 195). La literatura fantástica está poblada de «desdoblamientos» en criaturas nocturnas y siniestras y La misteriosa desaparición de la marquesita de Loria se resuelve como novela perteneciente a ese género. En ese contexto, Archibaldo Arenas es el fenómeno de borde, el jefe de una manada, el anomal en el sentido deleuzeano, quien lleva a Blanca a involucionar y devenir otro. Luna, el perro, es sólo uno de sus fantasmales devenires que desorientan la lectura y desplazan la novela desde el género erótico al fantástico. La continua frustración de la unión erótica entre Blanca y Luna se explica a partir de la distancia que todo devenir establece con un mundo de relaciones significantes. Si Blanca experimenta un devenir a través de su contacto con la multiplicidad que representa el perro (emisario de Archibaldo), entonces es claro por qué no se produce el bestialismo que el lector espera como el corolario pornográ-
La contrautopía pornográfica en misteriosa desaparición de Marquesita de Loria

MARÍA LUISA MARTÍNEZ M. 
8

La imposibilidad de la utopía en La misteriosa desaparición de la marquesita de Loria puede relacionarse con el contexto sociopolítico en el que se inserta su publicación. La novela, con un tono aparentemente frívolo y ligero, expone la decadencia propia del mundo narrativo donosiano. La novela se publica un año antes de que el autor vuelva a Chile en pleno Gobierno Militar $y$, desde esa perspectiva, la historia de la marquesita puede entenderse como metáfora de la desintegrada realidad chilena, devastada por la violencia que se expresó, entre otras cosas, en la gran cantidad de detenidos y desaparecidos. La superficialidad que subyace en el erotismo de la primera parte de la novela es una amarga sátira que esconde, detrás de la máscara fantástica en la que deviene la narración, una realidad terrible.

La contrautopía pornográfica en La misteriosa desaparición de la Marquesita de Loria

MARÍA LUISA MARTÍNEZ M. fico de la novela. Deleuze y Guattari señalan que el afecto guía los devenires entre multiplicidades, pero este afecto no es del tipo que expresan los seres humanos: «El anomal no es ni individuo ni especie, sólo contiene afectos, y no implica sentimientos familiares o subjetivos, ni caracteres específicos o significativos. Tanto las caricias como las clasificaciones humanas le son extrañas» $(2000$, p. 250). La unión sexual entre Blanca y Luna está descartada, porque el afecto que los vincula no se despliega en el territorio de lo humano, comúnmente sublimado a través de lo sexual. El gradual desinterés de Blanca por las diversas opciones eróticas que proponen sus amantes, quienes no logran colmar sus expectativas, permiten comprender la novela como una contrautopía pornográfica ${ }^{8}$. La marquesita, al igual que $\mathrm{O}$, la protagonista de la novela de Pauline Réage, busca trascender la propia personalidad, pero no lo hace a través de un proceso de elevación a partir de la propia degradación sexual, como señala Sontag: «O no se identifica sencillamente con su estado de disponibilidad sexual, sino que desea alcanzar la perfección de convertirse en objeto» (1997, p. 85). La realización de Blanca no es sexual, ni tampoco puede hablarse de degradación, a pesar del deterioro físico que experimenta a partir de las marcas que el perro deja en ella $\mathrm{y}$ en su entorno. Al contrario, en el caso de la marquesita se produce una involución enriquecedora en términos personales, porque le permite la liberación total de las ataduras sociales a partir de un soñar en sentido contrario y de la heterotopía de su habitación, que se convierte en un reino de destrucción:

Que su bello cuarto estuviera tan, o más, devastado que sus pobres uñas, la tenía, en cierta medida, sin cuidado: aquí no había pasado nada si ella no se dejaba asediar por el terror. Esta casa, al fin y al cabo, era su casa. Tenía derecho a decidir qué cosas que sucedían en ella sucedían de verdad, y cuáles, callándolas, no sucedían en absoluto (p. 123).

La marquesita no intenta retener la fortuna que Casilda le arrebata en concomitancia con uno de los Mamertos, porque el poder al que aspira traspasa las consideraciones mundanas, sociales y económicas. La nueva fuerza y poder que Blanca ostenta y ejerce es de carácter disolvente a partir del encuentro con el perro $\mathrm{y}$ «el vacío de sus ojos amarillos» (p. 146) que la empujan hacia un devenir imperceptible.
El movimiento, para Deleuze, mantiene una relación especial con lo imperceptible; el devenir se manifiesta como velocidades y lentitudes que atraviesan umbrales de percepción relativos y, de esa manera, devenir imperceptible implica involucionar, pasar inadvertido, ocultarse, camuflarse, devenir clandestino. La involución de Blanca se expresa fundamentalmente a partir de dos elementos significativos: su estaticidad cada vez mayor (al final de la novela, la marquesita se mantiene indiferente al intento de seducción de Casilda y se encierra en su habitación, donde permanece acodada en la ventana mientras mira lloviznar y escucha los ladridos de Luna) y la simplicidad y sobriedad que adopta al despojarse de todo rasgo accesorio (tras su desaparición, sólo se encuentran los lujosos objetos de los que se desprende definitivamente: el reloj, la hebilla de plata de su sombrero y un zapato francés). El perro, como un emisario del pintor o como uno de sus rostros, comparte la involución de Blanca; incluso parece no existir para nadie, excepto para la marquesita. La novela da múltiples indicios de que Blanca y Luna son una sola entidad, lo que explica que el perro pase inadvertido, que nadie escuche sus ladridos o que sea invisible para los demás personajes. La fuerza maléfica del perro contagia a la protagonista del poder demónico que ostenta al final de la novela, cuando ya ha barrido las convenciones y no pretende salvar las apariencias:

Bajando la escalera de mármol con su perro gris al lado, sintió que su autoridad sobre los sirvientes era tal que de hecho borraba al perro que la acompañaba, y ellos, obedientes, no lo veían descender escalón tras escalón con su pareja (p. 155).

La traición de la marquesita al mundo de relaciones significantes que gobiernan su esfera la lleva a huir de un rostro reconocible. Deleuze y Guattari señalan «que si el hombre tiene un destino, ése sería el de escapar del rostro, deshacer el rostro y las rostrificaciones, devenir imperceptible, devenir clandestino» (2000, p. 176). El corte de pelo de Blanca contribuye a otorgarle una nueva imagen, irreconocible: «En el lavabo se cortó el pelo con una tijera y una navaja, cruel, ásperamente, hasta quedar con cabeza de pillete» (p. 139). Es una de sus últimas rebeliones y es de gran importancia, porque con ese gesto simbólico rompe las ataduras que la atan 
sensualmente a Archibaldo Arenas, quien le había prohibido que se hiciera un corte a la garçon.

La literatura excitante prolonga el goce a través de la repetición para alcanzar la utopía de los sentidos. La misteriosa desaparición de la marquesita de Loria prolonga el placer por medio de su postergación y lo conjuga, en una cadena de múltiples devenires que la sexualidad despliega, con el carácter fantástico del relato. El devenir de Blanca, primero animal y luego imperceptible, la acerca a zonas de indiscernibilidad con nuevas entidades y con los nuevos rostros que éstas le ofrecen como liberación y salvación del hastío.

\section{Bibliografía}

Bataille, Georges (1997), El erotismo, Barcelona, Tusquets Editores.

Borinsky, Alicia (1997), «José Donoso: el otro coloquio de los perros, en Luis Gómez Canseco, Pablo Zambrano Carballo y Laura Alonso (editores), El sexo en la literatura, España, Servicio de publicaciones de la Universidad de Huelva, pp. 903-1004.

Chevalier, J.; Cheerbrant, A. (1995), Diccionario de los simbolos, Barcelona, Herder.

Deleuze, G.; Guattari, F. (2000), Mil mesetas. Capitalismo y esquizofrenia, Valencia, Pre-textos.

Donoso, José (1997), La misteriosa desaparición de la marquesita de Loria, Santiago de Chile, Alfaguara.

Fischer, Carolin (1997), Gärten der Lust, Stuttgart-Weimar, J. B. Metzler.

Foucault, Michel (2010), El cuerpo utópico. Las heterotopias, Buenos Aires, Nueva Visión.

Gnutzmann, Rita (1991), «Teoría y práctica del lector implícito», en Revista de literatura, LIII: 105, pp. 5-17.

Iser, Wolfgang (1993), «La estructura apelativa de los textos», en Dietrich Rall (comp.), En busca del texto, México, UNAM, pp. 99-119.
- (1987), El Acto de Leer, Madrid, Taurus Ediciones.

Jürgensen, Manfred (1985), Beschwörung und Erlösung, Bern-Frankfurt am Main, New York, Peter Lang Verlag.

Noguerol Jiménez, Francisca (1997), «De marquesas y zoofilia», en Luis Gómez Canseco, Pablo Zambrano Carballo y Laura Alonso (editores), El sexo en la literatura, Servicio de publicaciones de la Universidad de Huelva, pp. 231-246.

Pearson, Lon (1982), «Perros y símbolos en la narrativa de José Donoso», en Signos, XIII: 18, pp. 4-15.

Pérez Blanco, Lucrecio (1997), «Acercamiento a una novela de denuncia social: $L a$ misteriosa desaparición de la marquesita de Loria», en Luis Gómez Canseco, Pablo Zambrano Carballo y Laura Alonso (editores), El sexo en la literatura, Servicio de publicaciones de la Universidad de Huelva, pp. 399-410.

Rico, Joaquín (1983), «La teoría de la recepción literaria», en Arbor, CXVI: 455, pp. 15-33.

Solotorevsky, Myrna (1997), «La misteriosa desaparición de la marquesita de Loria o la frustración de lo erótico», en Luis Gómez Canseco, Pablo Zambrano Carballo y Laura Alonso (editores), El sexo en la literatura, España, Servicio de publicaciones de la Universidad de Huelva, pp. 81-103.

Sontag, Susan (1997), «La imaginación pornográfica», en Estilos radicales, Madrid, Santillana (Taurus), pp. 57-109.

Todorov, Tzvetan (1975), The fantastic: a structural approach to a literary genre, New York, Cornell University Press.

Valenzuela, Luisa (1997), «De la Manuela a la marquesita avanza el escritor custodiado (o no) por los perros del deseo", en $E l$ sexo en la literatura, Servicio de publicaciones de la Universidad de Huelva, pp. 1005-1008.

Fecha de recepción: 29/07/2011

Fecha de aprobación: 19/10/2011
La contrautopía pornográfica en La misteriosa desaparición de l Marquesita de Loria

MARÍA LUISA MARTÍNEZ M. 